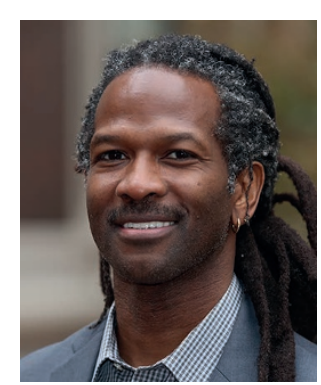

\title{
Viewing addiction as a brain disease promotes social injustice
}

\author{
The view of drug use and drug addiction as a brain disease serves to perpetuate \\ unrealistic, costly, and discriminatory drug policies, argues Carl L. Hart.
}

$\mathrm{M}$ ore than 25 years ago, I began studying neuroscience because I thought this approach would uniquely fix the 'drug problem'. At that time, I believed that the poverty and crime in the resource-poor community from which I came was a direct result of drug addiction; so, I reasoned that if I could cure addiction, especially through neural manipulations, I could fix the poverty and crime in my community. But, I learned that while cocaine - and other recreational drugs temporarily alters the functioning of specific neurons in the brains of all who ingest the drug, the vast majority of users never become addicted. And regarding the relatively small percentage of individuals who do become addicted, co-occurring psychiatric disorders and socioeconomic factors account for a substantial proportion of these addictions. To date, there has been no identified biological substrate to differentiate non-addicted persons from addicted individuals.

The notion that drug addiction is a brain disease is catchy but empty: there are virtually no data in humans indicating that addiction is a disease of the brain, in the way that, for instance, Huntington's or Parkinson's are diseases of the brain. With these illnesses, one can look at the brains of affected individuals and make accurate predictions about the disease involved and their symptoms.

We are nowhere near being able to distinguish the brains of addicted persons from those of non-addicted individuals. Despite this, the 'diseased brain' perspective has outsized influence on research funding and direction, as well as on how drug use and addiction are viewed in society. For example, the recently initiated multimillion-dollar Adolescent Brain Cognitive Development longitudinal study (https://addictionresearch. nih.gov/abcd-study) primarily seeks to gather neuroimaging data to better understand drug use and addiction among adolescents. It collects genetic information and measures drug use and academic achievement but lacks careful consideration of important social factors. Notably, there has never been such an ambitious funding effort focused on psychosocial determinants or consequences (for example, employment status, racial discrimination, neighbourhood characteristics, policing) of drug use or addiction.

This situation contributes to unrealistic, costly, and harmful drug policies. If the real problem with drug addiction, for example, is the interaction between the drug itself and an individual's brain, then the solution to this problem lies in one of two approaches. Either remove the drug from society through policies and law enforcement (for example, drug-free societies) or focus exclusively on the 'addicted' individual's brain as the problem. In both cases, there is neither need for nor interest in understanding the role of socioeconomic factors in maintaining drug use or mediating drug addiction.

The detrimental effects of using law enforcement as a primary means to deal with drug use are well documented. Millions are arrested annually for drug possession and the abhorrent practice of racism flourishes in the enforcement of such policies. In the United States, for example, cannabis possession accounts for nearly half of the 1.5 million annual drug arrests, and blacks are four times more likely to be arrested for cannabis possession than whites, even though both groups use cannabis at similar rates.

An insidious assumption of the diseased brain theory is that any use of certain drugs is considered pathological, even the non-problematic, recreational use that characterizes the experience of the overwhelming majority who ingest these drugs. For example, in a popular US anti-drug campaign, it is implied that one hit of methamphetamine is enough to cause irrevocable damage: http://www. methproject.org/ads/tv/deep-end.html.

In the 1980s, crack cocaine use was blamed for everything from extreme violence to high unemployment rates, premature death, and child abandonment. Even more frightening, addiction to the drug was said to occur after only one hit. Drug experts with neuroscience leanings weighed in. "The best way to reduce demand", Yale University psychiatry professor Frank Gawin was quoted to say in Newsweek (16 June 1986), "would be to have God redesign the human brain to change the way cocaine reacts with certain neurons."

'Neuro' remarks made about drugs with no foundation in evidence were pernicious: they helped to shape an environment in which there was an unwarranted and unrealistic goal of eliminating certain types of drug use at any cost to marginalized citizens. In 1986, the US Congress passed legislation setting penalties that were literally 100 times harsher for crack than for powder cocaine violations. More than $80 \%$ of those sentenced for crack cocaine offences are black, despite the fact that the majority of users of the drug are white. Today, many find the crack/powder laws repugnant because they exaggerate the harmful effects of crack and are enforced in a racially discriminatory manner, but few critically examine the role played by the scientific community in propping up the assumptions underlying these laws.

For their part, the scientific community has virtually ignored the shameful racial discrimination that occurs in drug law enforcement. The researchers themselves are overwhelmingly white and do not have to live with the consequences of their actions. I don't have this luxury. Every time I look into the faces of my children or go back to the place of my youth, I am forced to face the decimation that results from the racial discrimination that is so rampant in the application of drug laws and is abetted by arguments poorly grounded in scientific evidence.

We can no longer allow neuroexaggerations to determine our drug research funding priorities and directions, shape our views on drugs, nor our drug policies. The stakes are too high and the human cost is incalculable.

Carl L. Hart is the Dirk Ziff Professor and Chair of the Department of Psychology, and Professor in the Department of Psychiatry at Columbia University, Box 120, 1051 Riverside Drive, New York, New York 10032, USA.

e-mail: C.hart@columbia.edu

\section{Competing interests}

The author declares no competing interests. 